https://www.journal-imab-bg.org

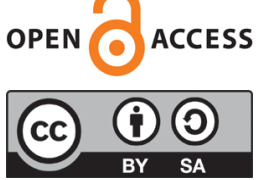

Case report

\title{
RECURRENCE OF ANEURYSMAL BONE CYST OF THE MANDIBLE: A CASE REPORT
}

\author{
Meri A. Hristamyan ${ }^{1}$, Rosen B. Tsolov ${ }^{2}$ \\ 1) Department of Epidemiology and Disaster Medicine, Faculty of Public \\ Health, Medical University of Plovdiv, Bulgaria. \\ 2) Clinic of Maxillofacial Surgery, St. George University Hospital, Plovdiv, Bul- \\ garia.
}

\begin{abstract}
Àneurysmal bone cysts are benign osteolytic lesions with rapid growth, thin walls containing numerous bloodfilled cavities. They occur mainly in the pediatric population but are rarely diagnosed in the facial skeleton. Although benign, the condition can be locally aggressive and cause significant weakening of the affected bone structure. This case report presents a 14-year-old boy with Burkitt's tumor (Non-Hodgkin's lymphoma), previously diagnosed with an aneurysmal bone cyst a year ago. He was admitted for treatment at the Clinic of Maxillo-Facial Surgery of the University Hospital "St. George" Plovdiv due to pain and swelling in the left molar area of the mandibula, dating from 2 days. A recurrence of an aneurysmal bone cyst measuring 55/25 mm, which does not require resection of the mandible, was found. After a decision for surgical removal of the formation, under general anesthesia, and preparation of a three-cornered mucoperiosteal flap, the mandibular bone, which is lysed and thinned by the formation, was trepanned. The roots of the affected teeth were resected, and the formation was extirpated. A gauze drain was placed in the formed cavity, and the wound was sutured. Drug therapy included Cefotaxime 2x1.0 - 10 days, starting 3 days before surgery, and Paracetamol 2x1 - 3 days, 2 days before and 1 day after surgery. Prophylactic examinations were scheduled on day $3,7,10,15$ after the operation, as well as 3,6 , and 12 months post-op, due to the recurrent nature of the formation.
\end{abstract}

Keywords: nonodontogenic, aneurysmal bone cyst, mandible, maxillofacial surgery,

\section{BACKGROUND}

An aneurysmal bone cyst(ABC)is a benign osteolytic lesion with rapid growth, thin walls containing numerous blood-filled cavities [1]. It was first described in 1893 as an ossifying hematoma by Van Arsdale [2, 3]. ABC is considered a result of a vascular malformation within the bone, though the ultimate cause of the malformation is still under debate [4]. It occurs mainly in the pediatric population [5], most commonly affecting individuals in their second decade of life and can occur in any bone in the body[6] but is rarely diagnosed in the facial skeleton [7]. ABC accounts for $1.5 \%$ of neodontogenic tumors of the jaw bones [8]. The average age of occurrence is 13 years, and $80 \%$ of patients are less than 20 years old with no gender predilection [9].

Histologically the ABC is considered a pseudocyst due to the absence of an epithelial wall. Recurrence is very typical, which confirms the aggressive behavior of this type of lesion [9].

Although nonodontogenic cysts of the jaws are relatively uncommon, it is imperative the clinician understand their clinical behavior and management because failure to do so can result in significantly increased patient morbidity [10]. Although benign, the condition can be locally aggressive and cause significant weakening of the affected bone structure. Strong pressure on the surrounding tissues in some cases can lead to deformities, neurological symptoms (depending on the location) and pathological fractures $[1,3]$. The etiology and pathophysiology are not yet clear [11], and currently, the standard of care and most widely used treatment is intralesional curettage [5].

\section{CASE DESCRIPTION}

The patient is a 14-year-old boy with a concomitant Burkitt's tumor (non-Hodgkin's lymphoma). He was admitted for the second time for treatment at the Clinic of Maxillo-Facial Surgery of the University Hospital "St. George" Plovdiv. At the first admission (12 months ago), he was diagnosed with an aneurysmal bone cyst measuring $24 / 37 \mathrm{~mm}$. in the area of teeth $34,35,36$, and the cyst was removed surgically by performing a cystectomy. The current admission was due to pain and swelling again in the left molar area of the mandibular bone, dating from 2 days.

The general status of the patient was without deviations. On extraoral examination, there was no facial asymmetry. Intraoral examination revealed normal poisoning of the mouth and a swollen vestibular plate of the lower jaw on the left side in the area of the molars, and on palpation, pain was provoked. A panoramic radiograph (orthopantomography) (Figure 1) revealed a cystic formation in the area of the lower jaw on the left. 
Fig. 1. Orthopantomography, showing cystic formation in the area of the lower jaw on the left.

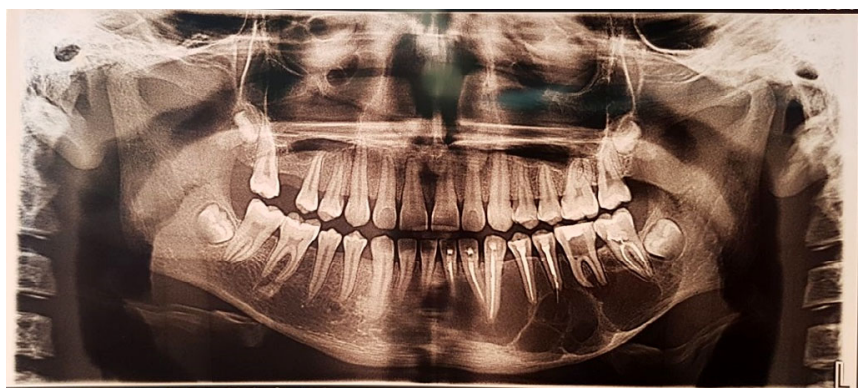

Due to the suspicion of a malignant process, after consultation with a pediatrician, a puncture was performed intraoperatively, and $35 \mathrm{ml}$. of blood was withdrawn (Figure 2). Pre-surgically, teeth 31, 32, 33, 34, 35, 37 were prepared endodotically, except for 36 , which did not allow treatment due to canal obliteration. A CT scan of the head was performed to specify the possible subsequent intervention. An expansilemulticystic lesion, representing a recurrence of an aneurysmal bone cyst measuring 55/ $25 \mathrm{~mm}$, which does not require resection of the mandible, was found.

Fig. 2. Withdrawal of blood from the cystic formation.

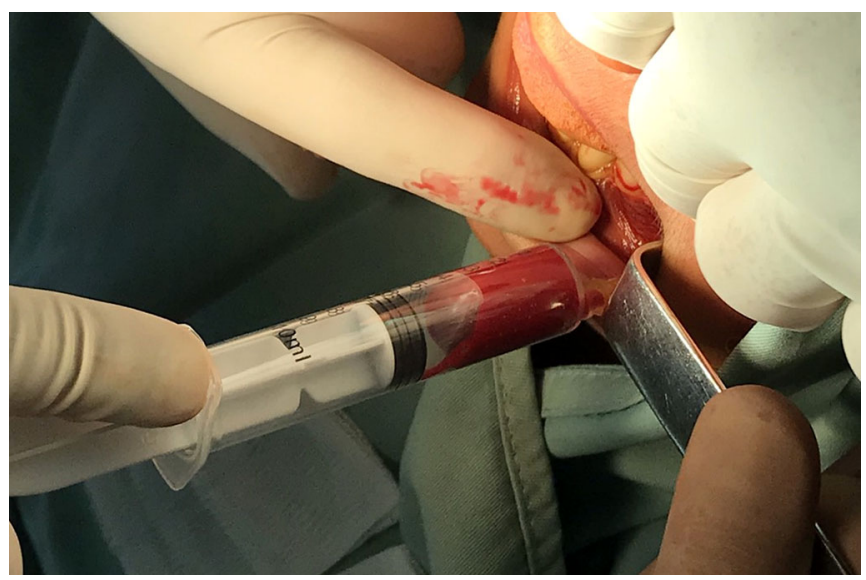

After a decision for surgical removal of the formation, under general anesthesia, and preparation of a threecornered mucoperiosteal flap in the area from the first incisive (31) to the last molar tooth (38) (Figure 3), the mandibular bone, which was lysed and thinned by the formation, was trepanned. The roots of the affected teeth were resected, the formation was extirpated and then sent for histological examination, with the morphological results corresponding to the clinical diagnosis (Figure 4). A gauze drain was placed in the formed cavity, and sutures (Figure 5) were placed, which were removed on day 10 post-op.
Fig. 3. Preparation of three-cornered mucoperiosteal flap.

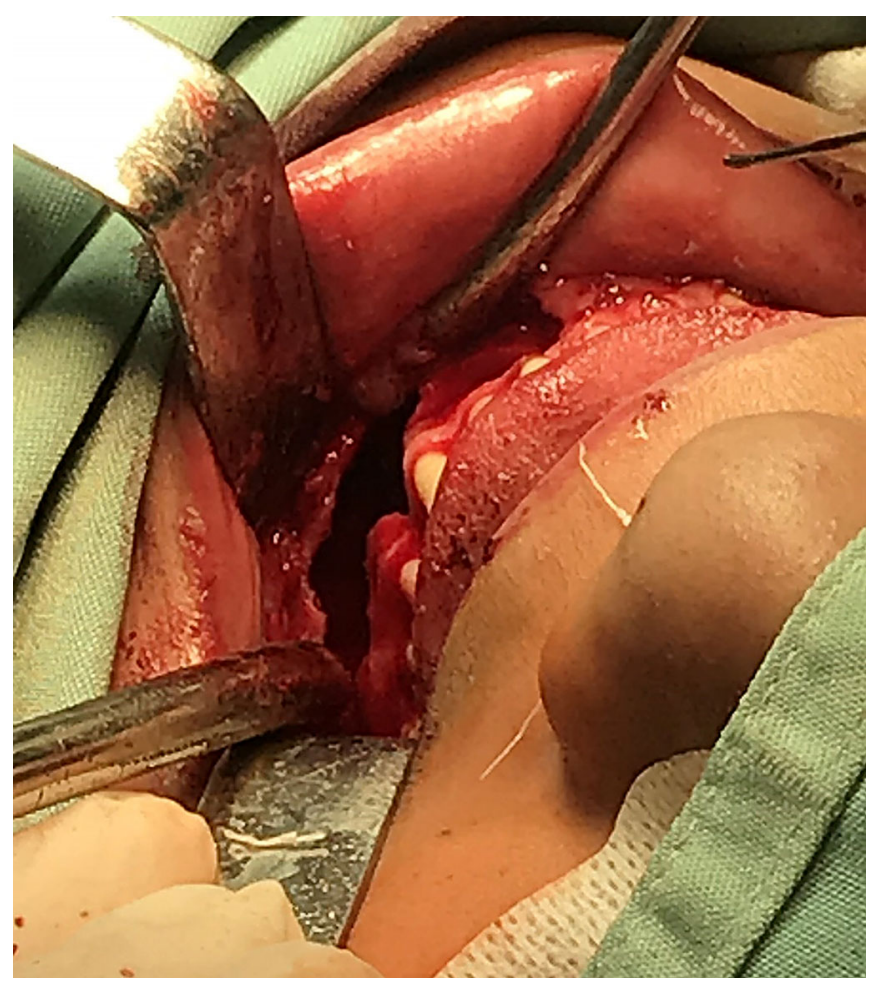

Fig. 4. The extirpated cystic formation sent for histological examination.

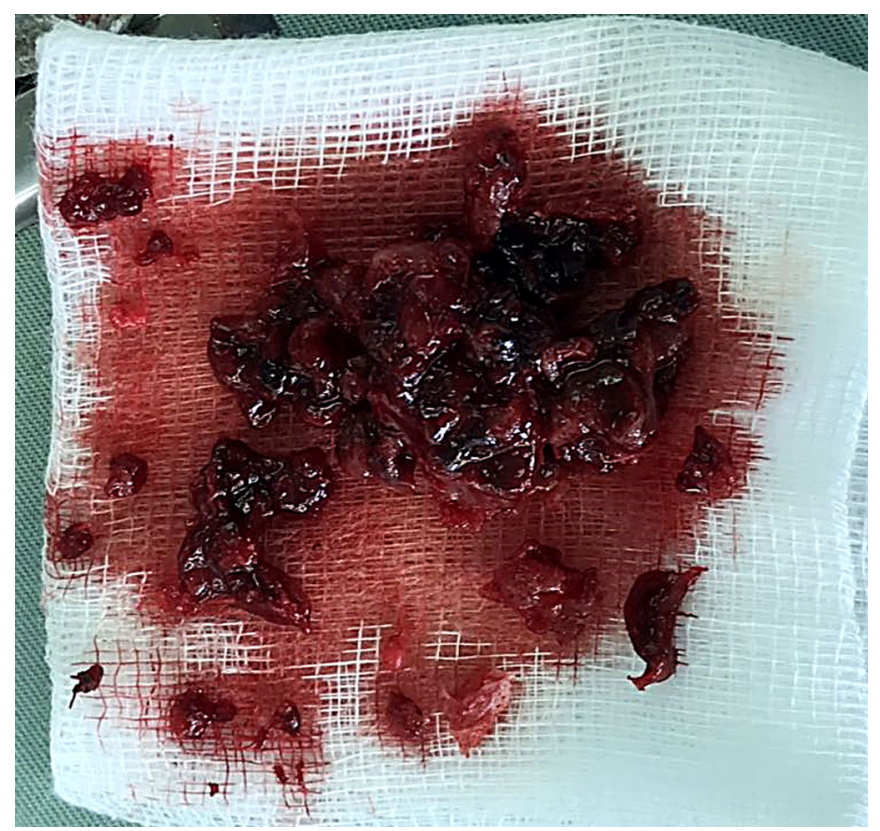


Fig. 5. Check-up 3 days after the operation.

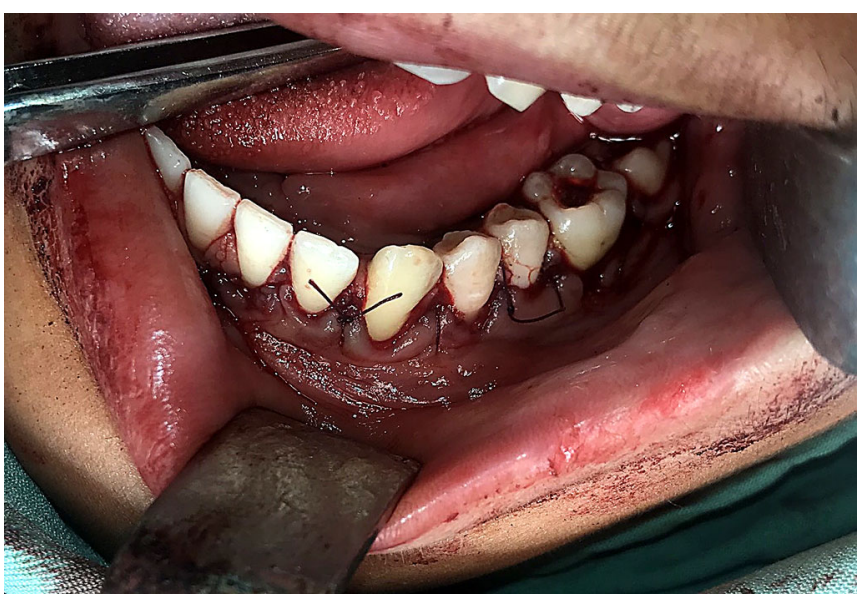

Drug therapy included Cefotaxime 2x1.0 - 10 days, starting 3 days before surgery, and Paracetamol 2x1 - 3 days, 2 days before and 1 day after surgery. Prophylactic examinations were scheduled on days $3,7,10,15$ after the operation, as well as 3, 6, and 12 months post-op, due to the recurrent nature of the formation. The patient made an uneventful recovery.

\section{DISCUSSION}

It is well documented that cysts within the pediatric population tend to be developmental and odontogenic in nature. Nonodontogenic cysts within the jaws, such as $\mathrm{ABC}$, are not a common finding in either the adult or pediatric patient population [10]. Bernier and Bhaskar described the first case of $\mathrm{ABC}$ in the jaws in 1958 [12]. $\mathrm{ABC}$ accounts for $1.5 \%$ of the nonodontogenic, nonepithelial cysts of the mandible [8]. It is found more frequently in the mandible than the maxilla (3:1) with preponderance for the body, ramus and angle of the mandible [11] and rarely affects the condyles [13, 14].

$\mathrm{ABC}$ have been classified as primary and secondary, where primary may be divided into congenital or acquired types [3]. Histopathologically, the vascular variant is more common and consists of about $95 \%$ of total cases of $\mathrm{ABC}$, while the solid type is rare, occurring in only $5-8 \%$ of cases $[7,13]$.

$\mathrm{ABC}$ is a lesion with a unique clinical, radiological and diagnostic finding [14]. Although pediatric jaw lesions are uncommon, symptoms such as swelling and pain could indicate potential pathologic findings and require panoramic examination [15]. Patients usually undergo different modalities of imaging, namely X-ray, CT and MRI, which show an expansilemulticystic lesion of the respective bone site [16].

Management of pediatric jaw lesions should consider the biologic behavior of the lesion, maxillofacial development, and growth [15]. Curettage, bone grafting, or resection are the common types of surgical treatment. Currently, the standard of care and most widely employed treatment is intralesional curettage. However, tumor recurrence with curettage alone is common and has driven some to propose a multitude of adjuvants with varying efficacy and risk profiles [5]. For some clinicians, the treatment of choice is surgical resection, considering the high recurrence rate [7].

In a review of the literature, curettage or resection was employed equally, and recurrence rates were $60 \%$ after curettage, $20 \%$ after resection. All recurrences occurred within 12 months, correlating with the presented case report [17].

Some authors consider drug treatment and state that denosumab provided a meaningful clinical and radiological improvement in $\mathrm{ABC}$; however, studies with more cases are required for routine use of denosumab in ABC [18].

\section{CONCLUSION}

Maxillofacial $\mathrm{ABCs}$ are rare lesions with variable clinical and histological presentations. Treatment of choice is most commonly curettage, or in some cases resection, depending mostly on the location and size of the formation, as well as on the biologic behavior of the lesion and maxillofacial development in young individuals which it predominantly affects. Due to the high recurrence rate of $\mathrm{ABC}$, a close post-operative follow-up for at least 12 months is recommended.

\section{Abbreviations: \\ ABC - Aneurysmal bone cyst \\ CT - Computer tomography \\ MRI - Magnetic resonance imaging}

\section{Acknowledgements:}

The paper was supported by the Ministry of Education and Science, Republic of Bulgaria (National program "Young scientists and postdoctoral students").

\section{REFERENCES:}

1. Mehboob J, Aleem U, Asghar AH. Aneurysmal bone cyst of the occipital bone. J Coll Physicians Surg Pak. 2011 Oct;21(10):628-30. [PubMed]

2. Van Arsdale WW. II. Ossifying Haematoma. Ann Surg. 1893 Jul; 18(1):8-17. [PubMed]

3. Gadre KS, Zubairy RA. Aneurysmal bone cyst of the mandibular con- dyle: report of a case. J Oral Maxillofac Surg. 2000 Apr;58(4): 439-43. [PubMed]

4. Cottalorda J, Bourelle S. Modern concepts of primary aneurysmal bone cyst. Arch Orthop Trauma Surg. 2007; 127:105-14. [PubMed]

5. Park HY, Yang SK, Sheppard WL, Hegde V, Zoller SD, Nelson SD,
Federman N, Bernthal NM. Current management of aneurysmal bone cysts. Curr Rev Musculoskelet Med. 2016 Dec;9(4):435-444. [PubMed]

6. Tedesco N, Eastwood B. Aneurysmal Bone Cyst. Medscape. Apr 15, 2019. [Internet]

7. Pelo S, Gasparini G, Boniello R, Moro A, Amoroso PF. Aneurysmal 
bone cyst located in the mandibular condyle. Head Face Med. 2009 Feb 16;5:8. [PubMed]

8. Marin Fernandez AB, Garcia Medina B, Martinez Plaza A, AguilarSalvatierra A, Gómez-Moreno G. Aneurysmal bone cyst of the mandible affecting the articular condyle: a case report. Clin Case Rep. 2016 Oct 28;4(12):1175-1180. [PubMed]

9. Segall L, Cohen-Kerem R, Ngan BY, Forte V. Aneurysmal bone cysts of the head and neck in pediatric patients: a case series. Int J Pediatr Otorhinolaryngol. 2008, 72:977-83. [PubMed]

10. Jones RS, Dillon J. Nonodontogenic Cysts of the Jaws and Treatment in the Pediatric Population. Oral Maxillofac Surg Clin North Am. 2016 Feb;28(1):31-44. [PubMed]

11. Devi P, Thimmarasa V
Mehrotra V, Agarwal M. Aneurysmal bone cyst of the mandible: A case report and review of literature. J Oral Maxillofac Pathol. 2011 Jan;15(1): 105-8. [PubMed]

12. Bernier JL, Bhaskar SN. Aneurysmal bone cysts of the mandible. Oral Surg Oral Med Oral Pathol. 1958 Sep;11(9):1018-28. [PubMed]

13. Kar IB, Mishra N, Ukey RB, Chopda PD. Unusual mandibular condylar pathology: Aneurysmal bone cyst, a case report and review on reconstruction. Natl J Maxillofac Surg. 2015 Jan-Jun;6(1):123-6. [PubMed]

14. Campanacci M, Capanna R, Picci P. Unicameral and aneurysmal bone cysts. Clin Orthop. 1986; 204: 25-36. [PubMed]

15. Chen Y, Zhang J, Han Y, Troulis MJ, August M. Benign Pediatric Jaw Lesions at Massachusetts General
Hospital Over 13 Years. J Oral Maxillofac Surg. 2020 Jul;78(7): 11241135. [PubMed]

16. Parashari UC, Khanduri S, Upadhyay D, Bhadury S, Singhal S. Radiologic and pathologic correlation of aneurysmal bone cysts at unusual sites. J Cancer Res Ther. 2012 JanMar;8(1):103-5. [PubMed]

17. Zadik Y, Aktas A, Drucker S, Nitzan DW. Aneurysmal bone cyst of mandibular condyle: a case report and review of the literature. J Craniomaxillofac Surg. 2012 Dec;40(8): e243-8. [PubMed]

18. Kurucu N, Akyuz C, Ergen FB, Yalcin B, Kosemehmetoglu K, Ayvaz M, et al. Denosumab treatment in aneurysmal bone cyst: Evaluation of nine cases. Pediatr Blood Cancer. 2018 Apr;65(4). [PubMed]

Please cite this article as: Hristamyan MA, Tsolov RB. Recurrence of Aneurysmal Bone Cyst of the Mandible: A Case Report. J of IMAB. 2021 Oct-Dec;27(4):4139-4142. DOI: https://doi.org/10.5272/jimab.2021274.4139

Received: 31/05/2021; Published online: 06/12/2021

Address for correspondence:

Dr Meri Hristamyan, $\mathrm{PhD}$

Department of Epidemiology and DM, Faculty of Public Health, Medical University - Plovdiv,

15A, Vasil Aprilov Str., Plovdiv, Bulgaria

E-mail: mary_hr@abv.bg 